Sains Malaysiana 49(2)(2020): 305-313

http://dx.doi.org/10.17576/jsm-2020-4902-08

\title{
Incorporating 1-butyl-3-methylimidazolium Chloride Ionic Liquid into Iota Carrageenan Solid Biopolymer Electrolyte for Electrochemical Devices Application \\ (Pencampuran Cecair Ionik 1-butil-3-metilimidazolium Klorida ke dalam Elektrolit Biopolimer Pepejal Iota Karagenan bagi Aplikasi Peranti Elektrokimia)
}

\author{
Nur Azlina Abdul Ghani, Farah Hannan Anuar, Azizan Ahmad, Nadhratun Naimm Mobarak, Intan

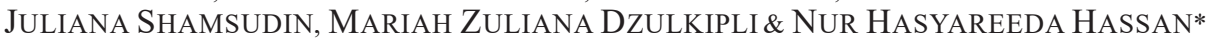

ABSTRACT

Solid biopolymer electrolyte based on iota carrageenan and 1-butyl-3-methylimidazolium chloride, [Bmim]Cl were successfully prepared by solution casting technique. Weight percentage (wt. \%) of [Bmim] Cl was varied from 0 wt. \% to $100 \mathrm{wt} . \%$ and the highest ionic conductivity achieved was $2.70 \times 10^{-3} \mathrm{~S} \mathrm{~cm}^{-1}$ for $70 \mathrm{wt} . \%$ [Bmim] Cl at ambient temperature. The interaction between iota carrageenan and [Bmim] Cl was confirmed by the formation of new peak on the ATR-FTIR spectrum. The reduction in crystallinity of iota carrageenan as the inclusion of [Bmim]Cl was observed based on X-ray diffraction (XRD) spectroscopy. FESEM morphology showed the compatibility and homogeneity between iota carrageenan and [Bmim] Cl while the LSV analysis showed that solid biopolymer electrolyte-based iota carrageenan[Bmim] Cl possess high electrochemical stability up to $3.0 \mathrm{~V}$. The transference number (TN) analysis indicated that ions are the main contributor for the ionic conduction.

Keywords: Iota carrageenan; ionic conductivity; ionic liquid; solid polymer electrolyte

\section{ABSTRAK}

Elektrolit biopolimer pepejal berasaskan iota karagenan dan 1-butil-3-metilimidazolium klorida, [Bmim]Cl berjaya dihasilkan melalui teknik pengacuan larutan. Peratus berat (\% bt.) [Bmim]Cl divariasikan daripada $0 \%$ bt. sehingga $100 \%$ bt. dan kekonduksian ionik tertinggi adalah $2.70 \times 10^{-3} \mathrm{~S} \mathrm{~cm}^{-1}$ bagi $70 \%$ bt. [Bmim]Cl pada suhu ambien. Interaksi antara iota karagenan dan [Bmim] Cl disahkan dengan pembentukan puncak baru pada spektrum ATR-FTIR. Pengurangan dalam penghabluran karagenan apabila [Bmim] Cl dimasukkan diperhatikan berdasarkan spektroskopi belauan sinar-X (XRD). Morfologi FESEM memperlihatkan keserasian dan kehomogenan antara iota karagenan dengan [Bmim]Cl manakala analisis LSV menunjukkan bahawa elektrolit biopolimer pepejal berasaskan iota karagenan[Bmim] Clmempunyai kestabilan elektrokimia yang tinggi sehingga 3.0 V. Analisis nombor pemindahan (TN) membuktikan bahawa ion adalah penyumbang utama bagi pengkonduksian ionik.

Kata kunci: Cecair ionik; elektrolit biopolimer pepejal; iota karagenan; konduksian ionik

\section{INTRODUCTION}

Biopolymers offer renewable, abundant, biodegradable and non-hazardous properties compared to synthetic polymers (Mobarak et al. 2015; Shamsudin et al. 2015a, 2015b). Previous studies showed that biopolymer had the potential to be used in various applications such as drug delivery, water treatment and filler. Biopolymer also has the ability to function as a polymer host for solid polymer electrolyte application (Agrawal \& Pandey 2008; Ng \& Mohamad 2006; Osman \& Arof 2003; Tanner et al. 2002).

Carrageenan, which is extracted from red seaweed (Rhodophyceae) is a family of anionic polymers that share a common backbone of alternating $(1 \rightarrow 3)$-linked $\beta$-Dgalactopyranose and $(1 \rightarrow 4)$-linked $\alpha$-Dgalactopyranose. There are three primary types of carrageenan: kappa (possesses one sulphate per disaccharide), iota (two sulphates per disaccharide) and lambda (three sulphates per disaccharide) (Borderias et al. 2005; Campo et al. 2009; Moniha et al. 2018). Normally, carrageenan has been used widely in food, pharmaceutical, and cosmetic industry as gelling agents, stabilizer and viscosity builder (Borderias et al. 2005; Coggins et al. 2000; Mobarak et al. 2015; Paula et al. 2015). Recent studies showed that carrageenan has potential to be used as host polymer as it managed to achieve ionic conductivity in the range of $10^{-8}-10^{-6} \mathrm{~S} \mathrm{~cm}^{-1}$ depends on types of carrageenan.

However, the minimum requirement of ionic conductivity for the electrolyte in order to be fabricated into electrochemical devices is in the range of $\times 10^{-3} \mathrm{~S}$ $\mathrm{cm}^{-1}$. In a study reported by Jumaah et al. (2014), the ionic conductivity of iota carrageenan was only $2.19 \times 10^{-8} \mathrm{~S}$ $\mathrm{cm}^{-1}$ (Jumaah et al. 2014, 2013). On the other hand, in our previous studies on a purified iota carrageenan, the ionic 
conductivity was found to be $1.57 \times 10^{-5} \mathrm{~S} \mathrm{~cm}^{-1}$ (Ghani et al. 2018). Guided by these results, imidazolium ionic liquid has been chosen to be added into a purified iota carrageenan. It is expected that the ionic conductivity will increase and electrochemical stability of iota carrageenan will be enhanced as ionic liquids can act as a carrier and plasticizer in the system. Ionic liquid is also known due to its negligible vapour pressure and low flammability that enhanced the safety features. Besides that, ionic liquids also possess a wide electrochemical window in the range of 2.0 to $5.0 \mathrm{~V}$ which is applicable to the electrochemical device application (Anderson et al. 2006; Armand et al. 2009; Liu et al. 2011; Sun \& Armstrong 2010).

1-Butyl-3-methylimidazolium chloride, [Bmim $] \mathrm{Cl}$ was chosen because of its compatibility and ability to dissolve biopolymer (Bester-Rogac et al. 2011; Liu et al. 2011). The high ionic conductivity value (Bester-Rogac et al. 2011; Vila et al. 2007) of [Bmim]Cl plays an important role as a charge carrier in the system. Besides that, Shamsudin et al. (2015a) also reported that the addition of [Bmim]Cl into carboxymethyl kappa carrageenan-based polymer electrolyte had achieved the highest ionic conductivity value of $5.76 \times 10^{-3} \mathrm{~S} \mathrm{~cm}^{-1}$ at $30 \mathrm{wt}$. $\%$ of $[\mathrm{Bmim}] \mathrm{Cl}$. They reported that $[\mathrm{Bmim}] \mathrm{Cl}$ does not only act as charge carriers but also as a plasticizer with the development of amorphous phase (Liew et al. 2014; Shamsudin et al. 2015a). Meanwhile, the electrochemical stability for [Bmim]Cl was up to $2.5 \mathrm{~V}$ as reported by Giridhar et al. (2007) and Jayakumar et al. (2007). They concluded that the utilization of [Bmim] $\mathrm{Cl}$ into the polymer electrolyte system not only had improved the ionic conductivity and amorphous phase of the electrolyte but also the electrochemical stability of the polymer electrolyte. Therefore, this study will discuss the effects of ionic liquid [Bmim] $\mathrm{Cl}$ on physical, chemical and electrochemical properties of iota carrageenan (Liew et al. 2014).

\section{MATERIALS AND METHODS}

\section{CHEMICALS AND MATERIALS}

Ionic liquid 1-butyl-3 methyl imidazolium chloride and acetic acid were purchased from Merck (Kenilworth, NJ, USA) and Sigma Aldrich (St. Louis, MO, USA). Iota carrageenan was purified prior to use. Other chemicals listed were used without further purification.

\section{PREPARATION OF FILM}

The purified iota carrageenan powder was dissolved in $1 \%$ solution of acetic acid and stirred overnight in order to ensure a complete dissolution of iota carrageenan (Mobarak et al. 2012). [Bmim] Cl was added to the solution of iota carrageenan at weight percentages (wt. \%) of $0,10,20$, $30,40,50,60,70,80,90$, and 100 under the nitrogen gas. The mixtures of purified iota carrageenan-[Bmim $] \mathrm{Cl}$ were stirred for $24 \mathrm{~h}$ at $40^{\circ} \mathrm{C}$. After that, each solution was poured into a Teflon petri dish and left to dry at room temperature for several days to allow complete evaporation of the solvent. The films formed were peeled and stored in a vacuum desiccator with silica gel desiccant for the further drying process.

\section{SAMPLE CHARACTERIZATION}

The ATR-FTIR analysis was performed using Perkin-Elmer Spectrum 2000 in the range $4000-650 \mathrm{~cm}^{-1}$. The analysis was carried out in order to investigate any shifting of the peak arising from the chemical interactions between iota carrageenan and $[\mathrm{Bmim}] \mathrm{Cl}$. The alternating current (AC) impedance measurements were conducted by using a highfrequency response analyser (HFRA) model Solartron 1260 Schlumberger in the frequency range of $1 \mathrm{~Hz}$ to $10 \mathrm{MHz}$ at room temperature. The polymer electrolytes were sandwiched between the stainless steel blocking electrodes with a contact surface area of $2.0 \mathrm{~cm}^{2}$. The bulk resistance, $R_{b}$ was analysed from the equivalent circuit analysis by using the Zview analyser software. The conductivity value $(\sigma)$ of the polymer electrolytes was calculated using equation $(\sigma)=t / R_{b} A$, where $t$ is the thickness of the film sample ranged between 0.03 and $0.08 \mathrm{~cm}$ and $A$ is the contact area. The X-ray diffraction (XRD) was performed using model D5000 Siemens. Data were collected ranging from $2 \theta$ from $3^{\circ}$ to $60^{\circ}$ at rate $0.05^{\circ} \mathrm{s}^{-1}$ to determine the level of amorphous properties of complexes. Investigation on the morphologies of the polymer electrolyte was examined using the FESEM Supra 55VP model at 10000 magnifications. The electrochemical stability window of the polymer electrolyte system was determined by applying the linear sweep voltammetry (LSV) technique in which the sample was placed between two stainless steel blocking electrodes using $1 \mathrm{mVs}^{-1}$ scan rate from 0 to $5 \mathrm{~V}$. The DC polarization method was used to measure the transference number (TN) of polymer electrolyte system in order to determine the main conducting element in the system. A fixed $1.0 \mathrm{~V}$ dc current was applied across the sample sandwiched between two stainless steels. The Wagner's polarization technique was applied to calculate the ion transference number, $t_{i o n}$ value from the current versus time plot by using equation $t_{i o n}=\left(I_{i}-I_{s s}\right) / I_{i}$ where $I_{i}$ and $I_{s s}$ are the initial and steady-state current, respectively.

\section{RESULTS AND DISCUSSION}

\section{INTERACTION STUDY}

The ATR-FTIR spectroscopy was utilized to investigate the interactions that occurred between the ionic liquid, [Bmim] $\mathrm{Cl}$ and polymer host, iota carrageenan. Figure 1 represents the infrared spectrum of the ionic liquid, iota carrageenan and iota carrageenan with different weight percentages of ionic liquid, [Bmim]Cl. We will focus on three different band regions between (a) 4000-2600 $\mathrm{cm}^{-1}$, (b) 1600-1300 $\mathrm{cm}^{-1}$ and (c) 1300-700 $\mathrm{cm}^{-1}$ that represent hydroxyl, carbonyl and ether groups as the interaction that was expected to occur between imidazolium cation and oxygen 


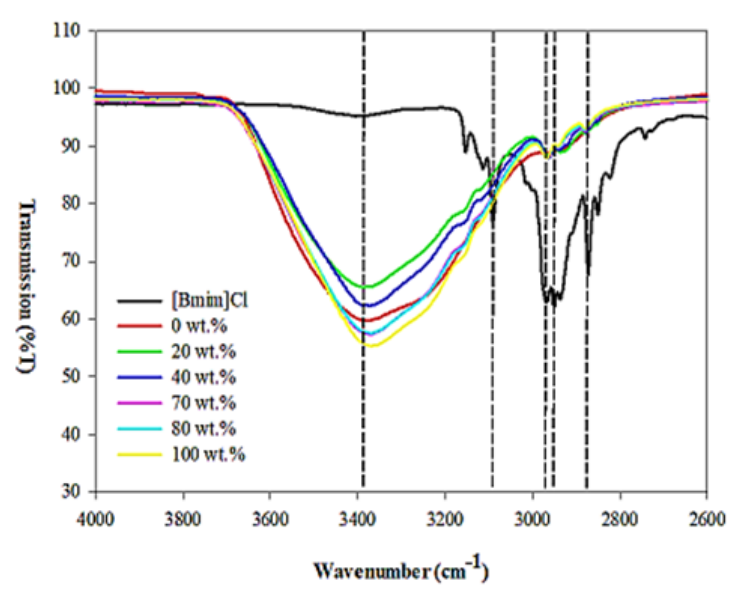

(a)



(b)

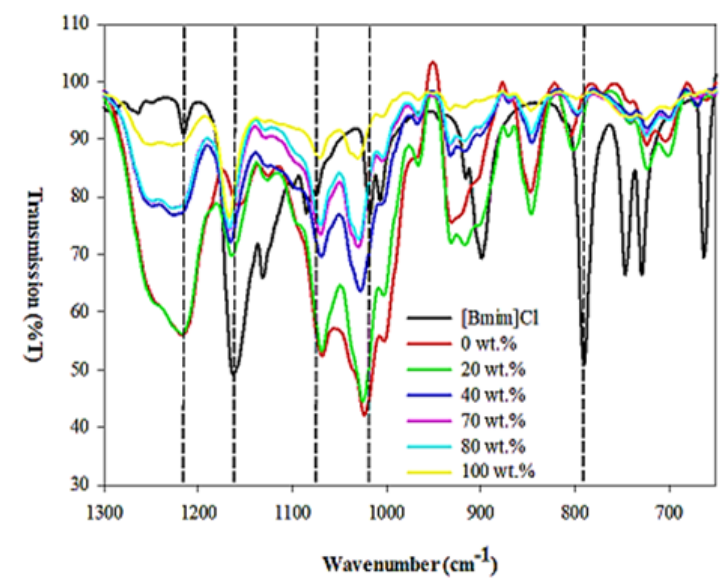

(c)

FIGURE 1. FTIR spectra of $[\mathrm{Bmim}] \mathrm{Cl}$ and iota carrageenan at different weight percentage of $[\mathrm{Bmim}] \mathrm{Cl}$

atoms. Based on Figure 1(a)-1(c)), there are four new peaks that can be observed when [Bmim] $\mathrm{Cl}$ was added into iota carrageenan. These new peaks represent $\mathrm{C}-\mathrm{H}$ stretching for cyclic $[\mathrm{Bmim}]^{+}$at $3152 \mathrm{~cm}^{-1}, \mathrm{C}-\mathrm{H}$ stretching of the methyl group of alkyl chain at $2967 \mathrm{~cm}^{-1}, 2958 \mathrm{~cm}^{-1}$ and $2876 \mathrm{~cm}^{-1}$, symmetric and asymmetric stretching of $\mathrm{CH}_{3}$ at $1464 \mathrm{~cm}^{-1}$ and $1430 \mathrm{~cm}^{-1}$ and $\mathrm{CH}_{3}-\mathrm{N}$ stretching mode of $[\mathrm{Bmim}]^{+}$at $1162 \mathrm{~cm}^{-1}$. Meanwhile, some of the characteristic bands of iota carrageenan experienced few changes in terms of wavenumber and intensity.

Based on the previous studies, the $\mathrm{O}-\mathrm{H}$ group in the iota carrageenan structure go through protonation as $1 \%$ acetic acid solution had been used as a solvent (Jumaah et al. 2014). The disappearance of $\mathrm{C}$-Cl stretching mode of [Bmim] Cl at $791 \mathrm{~cm}^{-1}$ on Figure 1(c) (Liew et al. 2014) can be observed. This phenomenon indicates the chloride dissociation from [Bmim] $\mathrm{Cl}$ and further interaction with $\mathrm{OH}_{2}^{+}$as chloride ion, $\mathrm{Cl}^{-}$has the ability to form an ionic bond with $\mathrm{OH}_{2}^{+}$(Claudio et al. 2014; Shamsudin et al. 2015a). The protonated $\mathrm{OH}$ and basic $\mathrm{Cl}^{-}$anion will exhibit electrostatic attraction that eventually pulls away the hydrogen from the centre atom (Shamsudin et al. 2015a). This resulted in the shifting of the $\mathrm{O}-\mathrm{H}$ stretch towards lower wavenumber for about $9 \mathrm{~cm}^{-1}$ because less energy is required to vibrate the particular bond (Shamsudin et al. 2015a). As the concentration of [Bmim $] \mathrm{Cl}$ was increased, the peaks that represented the $\mathrm{O}-\mathrm{H}$ group became more intense. These changes proved that there were interactions between the hydrogen of the hydroxyl group with chloride ions.

Meanwhile, the imidazolium cation, $[\mathrm{Bmim}]^{+}$which has the ability to donate hydrogen will form a coordination interaction with $\mathrm{C}-\mathrm{O}-\mathrm{H}, \mathrm{C}-\mathrm{O}-\mathrm{C}$ and $\mathrm{O}-\mathrm{SO}_{3}^{-}$. Basically, hydrogen at the $\mathrm{C} 2$ position of $[\mathrm{Bmim}]^{+}$has the most acidic hydrogen (H2) (Avent et al. 1994), therefore, possesses a high tendency to donate hydrogen to form a hydrogen bond with the $\mathrm{C}-\mathrm{O}-\mathrm{H}, \mathrm{C}-\mathrm{O}-\mathrm{C}$ and $\mathrm{O}-\mathrm{SO}_{3}{ }^{-}$groups. This interaction had caused the sharp peak of $\mathrm{CH}_{3}-\mathrm{N}$ stretching shifted from $1163 \mathrm{~cm}^{-1}$ to $1167 \mathrm{~cm}^{-1}$ with reduced peak intensity as shown in Figure 1(c) (Liew et al. 2014).

Besides that, the peaks at $1070 \mathrm{~cm}^{-1}, 1024 \mathrm{~cm}^{-1}$ and $1215 \mathrm{~cm}^{-1}$ which belong to C-O-H, C-O-C and a symmetric stretch of $\mathrm{O}=\mathrm{S}=\mathrm{O}$ had shifted to higher wavenumber regions, $1075 \mathrm{~cm}^{-1}, 1031 \mathrm{~cm}^{-1}$ and $1228 \mathrm{~cm}^{-1}$, respectively. The strong interaction of $\mathrm{H} 2$ in the imidazolium ring might have pushed the $\mathrm{C}-\mathrm{O}-\mathrm{H}, \mathrm{C}-\mathrm{O}-\mathrm{C}$ and $\mathrm{O}=\mathrm{S}=\mathrm{O}$ bond closer and thus shortened the bond length (Shamsudin et al. 2015). As a result, more energy is required to vibrate the bonds and resulted in the shift of wavenumber towards higher region as the concentration of $[\mathrm{Bmim}] \mathrm{Cl}$ increased. 


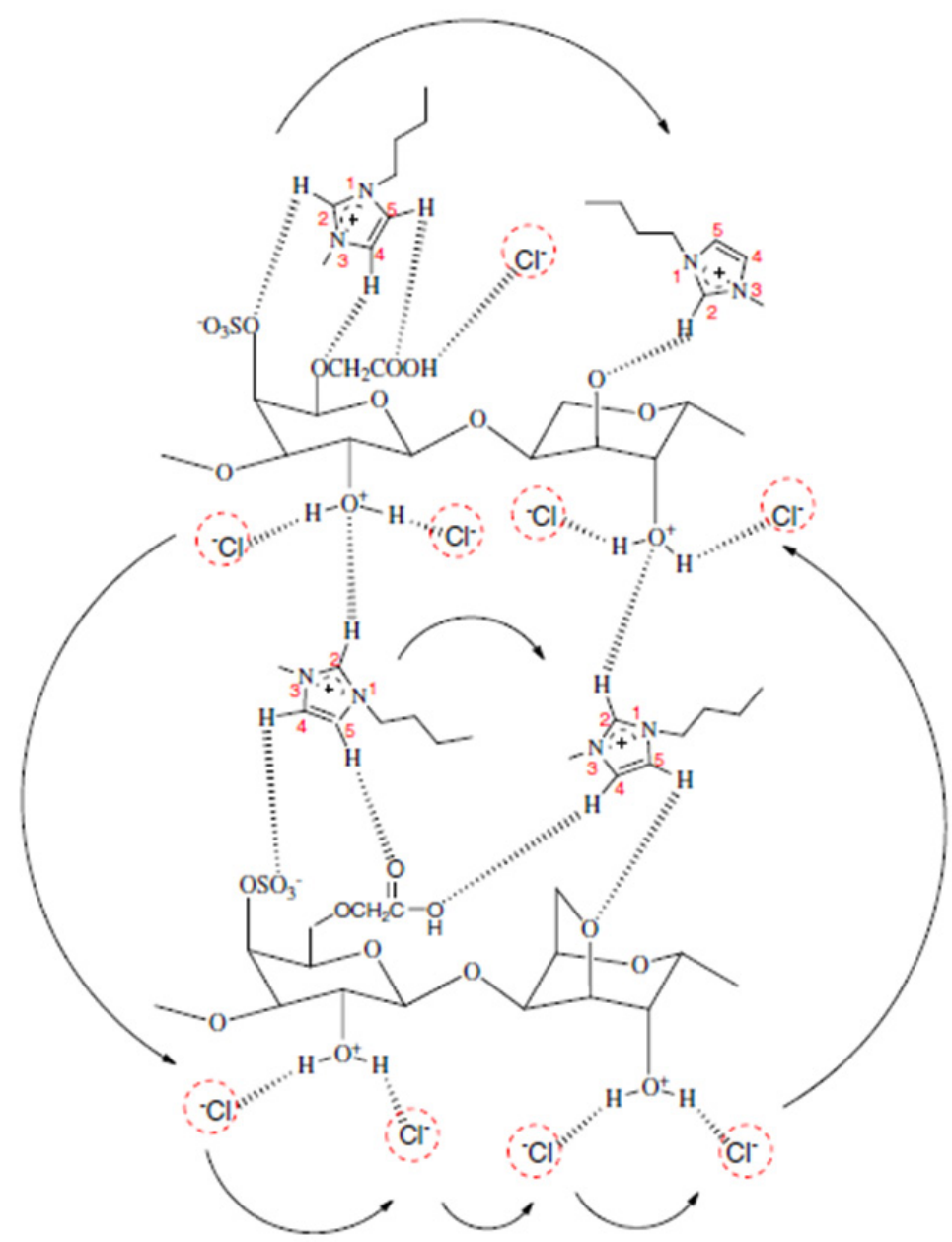

FIGURE 2. The proposed conduction mechanism of [Bmim]Cl with $\mathrm{CM}$-carrageenan reported by Shamsudin et al.(2015b)

Figure 1(b) shows the peak at $1556 \mathrm{~cm}^{-1}$ which belongs to the asymmetric stretch of carboxylate ion, $\mathrm{COO}^{-}$from acetate ion shifted to $1573 \mathrm{~cm}^{-1}$ as more [Bmim] $\mathrm{Cl}$ had been added. Carboxylate ion, $\mathrm{COO}^{-}$ion has the ability to interact with $\mathrm{H} 4$ and $\mathrm{H} 5$ located at $\mathrm{C} 4$ and $\mathrm{C} 5$ position in the imidazolium ring as it has the ability to form the resonance structures (Mobarak et al. 2015; Shamsudin et al. 2015a). Avent et al. (1994) stated that all hydrogen molecules in the imidazolium ring ( $\mathrm{H} 2, \mathrm{H} 4$ and $\mathrm{H} 5)$ are able to participate in the hydrogen bonding interaction (Avent et al. 1994). Thus, the resonance effects resulted in the attraction and repulsion of $\mathrm{COO}^{-}$ion with $\mathrm{H} 2, \mathrm{H} 4$ and $\mathrm{H} 5$ in imidazolium ring that will form a hydrogen bond with an anion, $\mathrm{COO}^{-}$. Furthermore, the bulky size of imidazolium cation, $[\mathrm{Bmim}]^{+}$will ensure the cation to keep intact with an anion, $\mathrm{COO}^{-}$in order to be mobile in this system.

The changes involved the $\mathrm{C}-\mathrm{O}-\mathrm{C}$ stretching of 3,6-anhydrogalactose at $930 \mathrm{~cm}^{-1}, \mathrm{C}-\mathrm{O}-\mathrm{C}$ stretch at 1024 $\mathrm{cm}^{-1}, \mathrm{O}=\mathrm{S}=\mathrm{O}$ symmetric stretching at $1215 \mathrm{~cm}^{-1},-\mathrm{O}-\mathrm{SO}_{3}$ stretching vibration of D-galactose-4-sulfate at $846 \mathrm{~cm}^{-1}$ and D-galactose-2-sulfate at $802 \mathrm{~cm}^{-1}$. These peaks were reduced in intensity as the $[\mathrm{Bmim}] \mathrm{Cl}$ increased, indicated the changes in the dipole moment of the molecule bonds
(Shamsudin et al. 2015a). Again, these observable changes signify the interaction between ionic liquid, [Bmim $] \mathrm{Cl}$ and iota carrageenan.

The changes in the ATR-FTIR spectra as the [Bmim] $\mathrm{Cl}$ was added into the iota carrageenan-based biopolymer electrolyte system suggest that ionic liquid, [Bmim $] \mathrm{Cl}$ acts as a charge carrier in this system. Imidazolium cation and chloride anion play an important role as mobile ion throughout the system by interacting with the active site of the polymer host, iota carrageenan. Hence, continuous coordination of the ions with the active site increased the ion mobility thus will generate the ionic conductivity. Shamsudin et al. (2015a) reported the proposed conduction mechanism of [Bmim] $\mathrm{Cl}$ with carboxymethyl carrageenan shown in Figure 2 that depicts a similar mechanism for the interaction between polymer host and the ionic liquid in this system.

\section{CRYSTALLINITY INDEX}

Figure 3 shows the X-ray diffraction pattern of iota carrageenan and iota carrageenan with 20, 40, 70, 80 and $100 \mathrm{wt}$ \% of [Bmim $] \mathrm{Cl}$. Iota carrageenan is a semicrystalline polymer that contains both crystalline and amorphous phase (Arof et al. 2010). However, the ionic conduction 


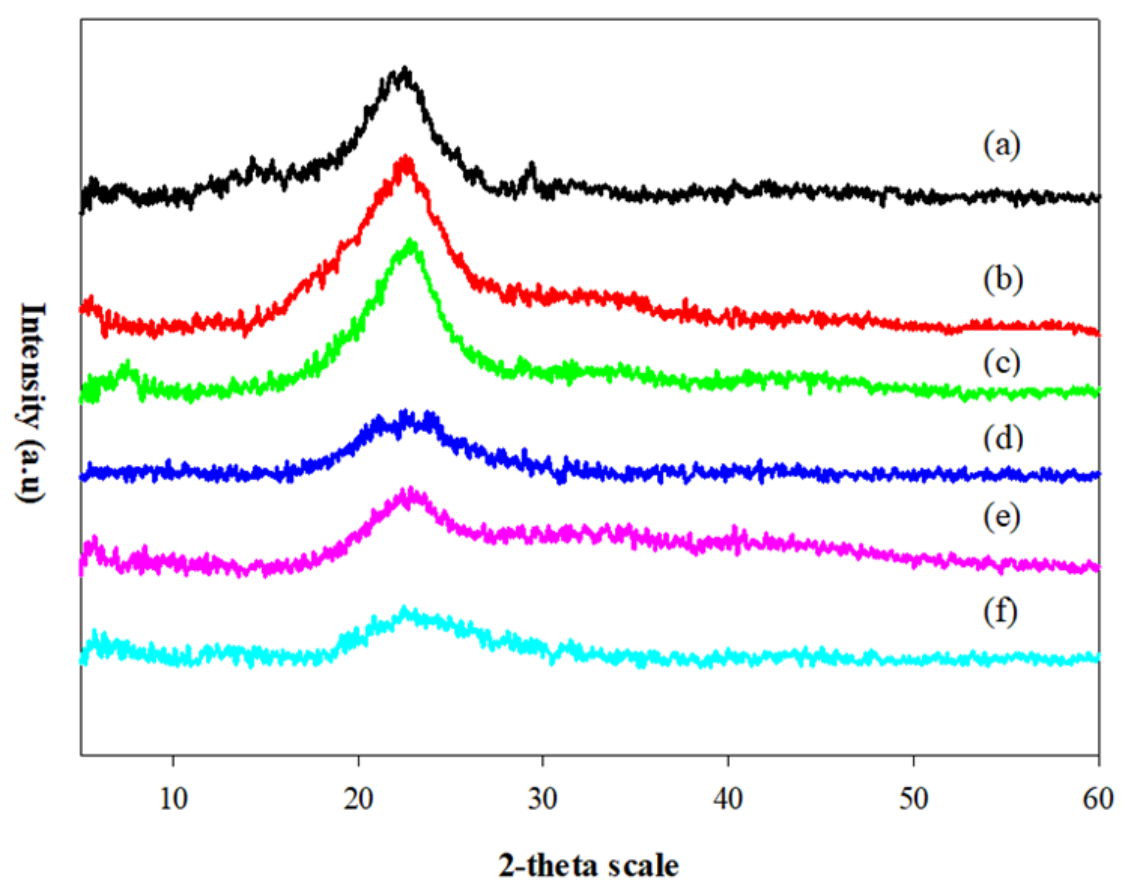

FIGURE 3. X-ray diffractogram of iota carrageenan at (a) 0 wt. \%, (b) 20 wt. \%, (c) 40 wt. \%, (d) $70 \mathrm{wt} . \%$, (e) $80 \mathrm{wt} . \%$ and (f) $100 \mathrm{wt} \%$ of $[\mathrm{Bmim}] \mathrm{Cl}$

takes place primarily in the amorphous region. Based on Figure 3, the crystallinity of iota carrageenan decreases upon the increasing concentration of the ionic liquid, $[\mathrm{Bmim}] \mathrm{Cl}$. The degree of crystallinity (DC) of the iota carrageenan is $36.9 \%$. Upon the addition of ionic liquid at 20 wt. $\%$ of $[\mathrm{Bmim}] \mathrm{Cl}$, the DC has decreased to $27.9 \%$ and gradually declined to $24 \%$ at $40 \mathrm{wt}$. $\%$ of [Bmim]Cl. At 70 wt. $\%$ of $[\mathrm{Bmim}] \mathrm{Cl}$, the polymer electrolyte system has achieved the lowest DC which is $14.1 \%$. The decrease in the $\mathrm{DC}$ value with the addition of $[\mathrm{Bmim}] \mathrm{Cl}$ into the iota carrageenan has proven that $[\mathrm{Bmim}] \mathrm{Cl}$ not only act as charge carrier but also give plasticizing effect in iota carrageenan system. However, the DC was then increased to $16.8 \%$ and $16.3 \%$ at $80 \mathrm{wt}$. $\%$ and $100 \mathrm{wt} . \%$ of [Bmim] $\mathrm{Cl}$ which is probably due to the high amount of ionic liquid loaded. This is also supported by impedance analysis result

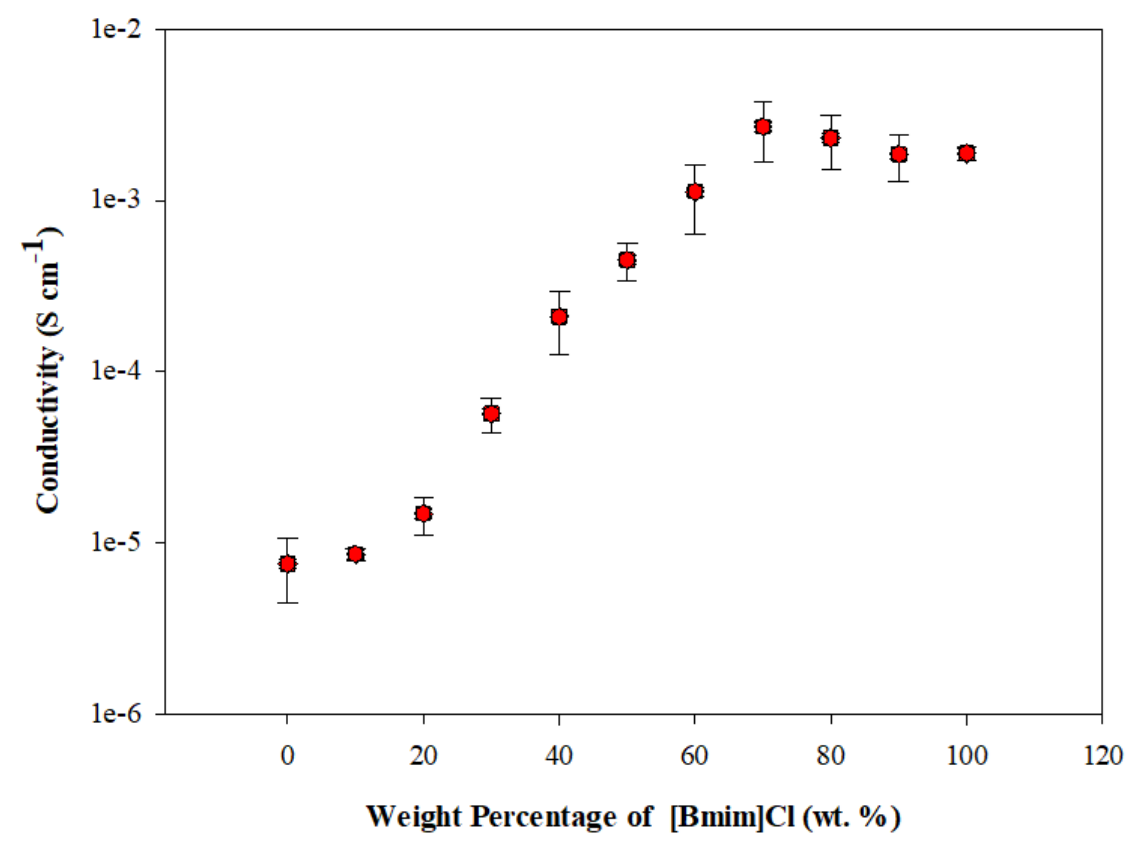

FIGURE 4. Ionic conductivity $(\sigma)$ of iota carrageenan as a function of [Bmim] $\mathrm{Cl}($ wt. $\%$ ) 
whereby the ionic conductivity started to drop at $80 \mathrm{wt} . \%$ and 100 wt. $\%$ of $[\mathrm{Bmim}] \mathrm{Cl}$.

\section{IONIC CONDUCTIVITY}

The ions of ionic liquid; imidazolium cation $[\mathrm{Bmim}]^{+}$and chloride anion $\mathrm{Cl}^{-}$interactions are weak and easily detached from each other due to the bulky size of the imidazolium cation (Shamsudin et al. 2014). Based on Figure 4, the ionic conductivity at ambient temperature of iota carrageenan was increased sequentially with the increasing concentration of $[\mathrm{Bmim}] \mathrm{Cl}$ concentration. The increment starts from $7.57 \times 10^{-6} \mathrm{Scm}^{-1}$ at 0 wt. $\%$ of $[\mathrm{Bmim}] \mathrm{Cl}$ to $1.48 \times 10^{-5} \mathrm{~S} \mathrm{~cm}^{-1}$ with the addition of $20 \mathrm{wt} . \%$ of $[\mathrm{Bmim}]$ $\mathrm{Cl}$. The optimum ionic conductivity value recorded was $2.70 \times 10^{-3} \mathrm{~S} \mathrm{~cm}^{-1}$ achieved at $70 \mathrm{wt} . \%$ of $[\mathrm{Bmim}] \mathrm{Cl}$ with the increment of ionic conductivity up to three orders of magnitude. The increment of ionic conductivity value is related to the increase of mobile charge carriers number in the iota carrageenan system and a decrease of crystallinity as proved by XRD spectrum.
However, the ionic conductivity gradually decreased upon addition of more than $70 \mathrm{wt} . \%$ of $[\mathrm{Bmim}] \mathrm{Cl}$. The decline in ionic conductivity in this system may be contributed by the re-association of ions. As the concentration of ionic liquid increases, the polymer host becomes saturated with ions which then lead to the formation of an ion pair and eventually, ion cluster. This reduces the number of mobile ions and hence, decreasing the ionic conductivity in the system (Rani et al. 2016; Woo et al. 2011).

\section{FESEM}

The morphology of iota carrageenan and iota carrageenan with $20,40,70,80$, and 100 wt. $\%$ of $[\mathrm{Bmim}] \mathrm{Cl}$ is depicted in Figure 5. Based on Figure 5(a), the morphology of 0 wt. $\%$ of $[\mathrm{Bmim}] \mathrm{Cl}$ shows the cratered surface of iota carrageenan film due to the semicrystalline nature of its polymer. Upon the addition of $20 \mathrm{wt} \%$ of [Bmim] $\mathrm{Cl}$, (Figure 5(b)) it can be seen that the addition of ionic liquid, [Bmim] Cl has altered the cratered surface of iota
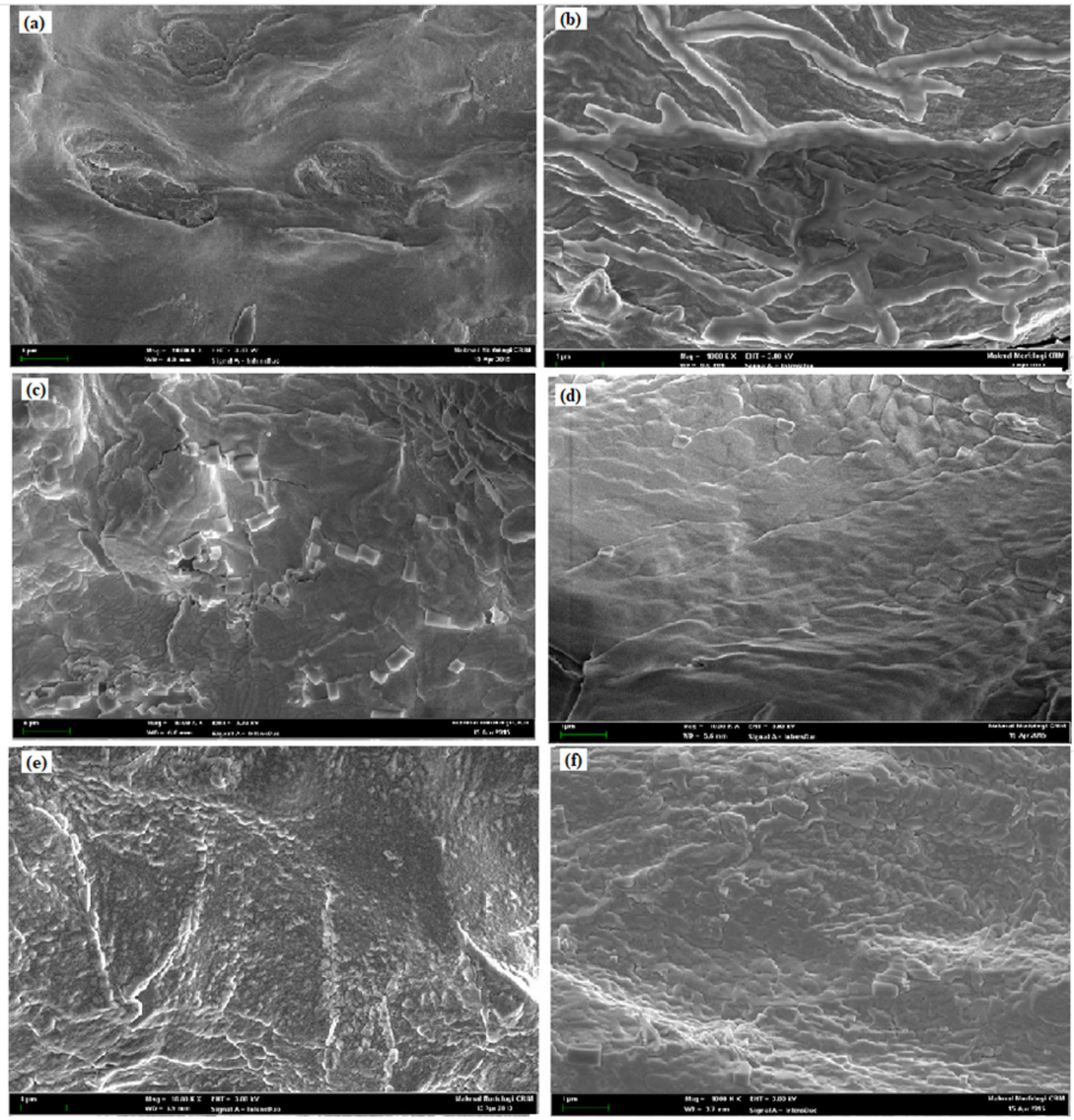

FIGURE 5. Surface morphology of (a) pure iota carrageenan film, (b) 20 wt. \%, (c) 40 wt. \%, (d) 70 wt. $\%$, (e) 80 wt. $\%$ and (f) 100 wt. $\%$ of [Bmim $] \mathrm{Cl}$ 


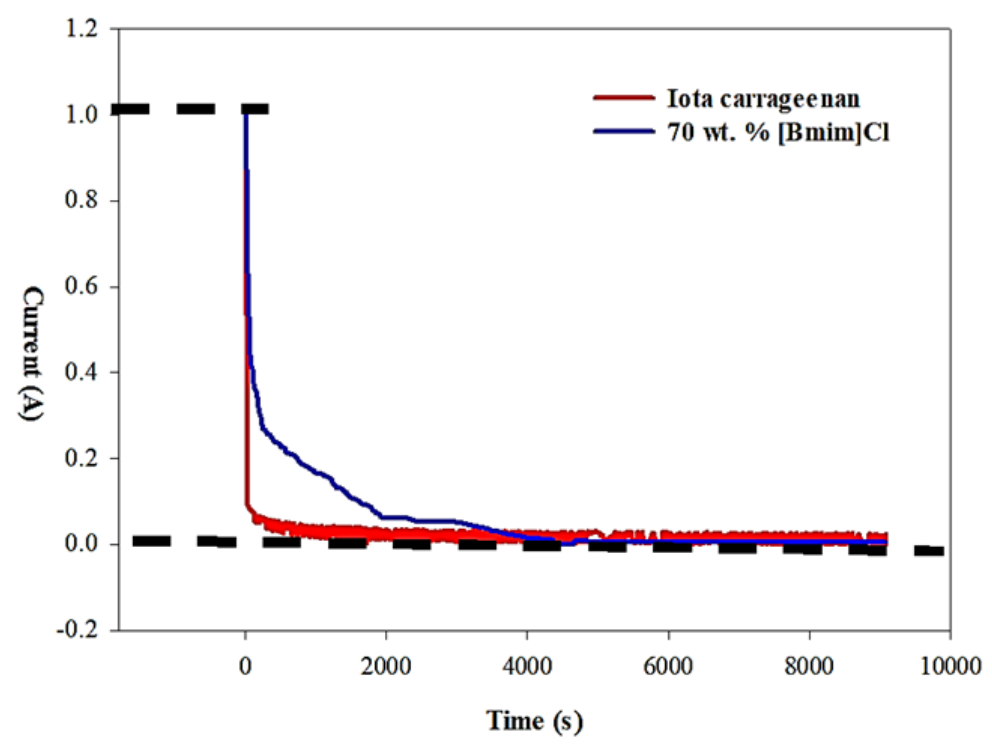

FIGURE 6. (a) Linear sweep voltammetry of pure iota carrageenan and iota carrageenan with $70 \mathrm{wt} . \%$ [Bmim]Cl,

(b) Current versus time of iota carrageenan and highest conducting iota carrageenan film at $70 \mathrm{wt} . \%[\mathrm{Bmim}] \mathrm{Cl}$

carrageenan film. At $40 \mathrm{wt}$. \% of [Bmim]Cl, the morphology of the film encountered some disruption and the rearrangement of the polymer has taken place as shown in Figure 5(c). Nevertheless, the homogeneity of the polymer electrolyte is achieved at $70 \mathrm{wt}$. $\%$ of $[\mathrm{Bmim}] \mathrm{Cl}$ as shown in Figure 5(d). This result shows the compatibility between iota carrageenan and $[\mathrm{Bmim}] \mathrm{Cl}$. Further increment of [Bmim $] \mathrm{Cl}$ at $80 \mathrm{wt} \%$ has caused the morphology of the electrolyte to become protruded and has less homogeneity compared to $70 \mathrm{wt}$ \% [Bmim] Cl (Figure 5(e)). The occurrence of this phenomenon can also be observed at 100 wt. \% [Bmim]Cl (Figure 5(f)). These morphological changes of the iota carrageenan polymer electrolyte have indicated that the plasticizing effects of [Bmim] $\mathrm{Cl}$ help to increase the ionic conductivity of the electrolyte with the development of an amorphous phase. Hence, the morphology study of iota carrageenan with the addition of different wt. $\%$ of the ionic liquid is in accordance with the XRD results of the polymer electrolytes.

\section{ELECTROCHEMICAL STABILITY}

Figure 6(a) depicts the linear sweep voltammetry (LSV) curves for the iota carrageenan and $70 \mathrm{wt}$. \% [Bmim $] \mathrm{Cl}$. A small current was observed through the working electrode until the applied voltage reached a potential of 2.8 and 3.0 $\mathrm{V}$ for iota carrageenan and $70 \mathrm{wt} . \%[\mathrm{Bmim}] \mathrm{Cl}$, respectively. This analysis provides information on the electrochemical stability of an electrolyte in which it notified the potential range where neither oxidation nor reduction is experienced by the electrolyte for it to be applied in the electrochemical device's applications. Figure 6(a) shows that iotacarrageenan exhibits electrochemical stability up to $2.8 \mathrm{~V}$ which is lower compared to iota carrageenan with $70 \mathrm{wt}$. $\%[\mathrm{Bmim}] \mathrm{Cl}$ in which the value is up to $3.0 \mathrm{~V}$ as shown in Figure 6(a). The anodic current was negligible below 2.0 $\mathrm{V}$ but then it increased gradually which might be attributed to the decomposition of the chloride anion (Shamsudin et al. 2015a). Hence, the utilization of ionic liquid has improved the stability of iota carrageenan electrolyte system as it increased dissociation of ion inside the polymer host.

\section{TRANSFERENCE NUMBER}

The transference number of the solid biopolymer electrolytes- based iota carrageenan with the ionic liquid, $[\mathrm{Bmim}] \mathrm{Cl}$ is depicted in Figure $6(\mathrm{~b})$. The value of the transference number was calculated from the normalized polarization current versus time. Based on the graph, the initial total current was found to decline with time due to the depletion of ionic species in the electrolytes and become constant in the fully depleted condition as shown in Figure 6(b). At steady state, the current flows because of the electronic species that migrate across the electrolyte and interfaces (Mobarak et al. 2015). Based on the calculated value, the $t_{i o n}$ for iota carrageenan was found to be 0.97 whilst the $t_{\text {ion }}$ with the addition of [Bmim] $\mathrm{Cl}$ was calculated to be 0.98 . Both of these values imply that ions are the main contributor to the ionic conduction of the electrolytes and the effects of the electrons which are 0.03 and 0.02 can be neglected for both systems. The increased value of $t_{\text {ion }}$ of 0.98 suggests the increased of ionic species in the system due to the incorporation of $[\mathrm{Bmim}] \mathrm{Cl}$.

\section{CONCLUSION}

The influence of ionic liquid on iota carrageenan based solid biopolymer electrolyte was investigated. The highest ionic conductivities achieved for iota carrageenan was 2.70 $\times 10^{-3} \mathrm{~S} \mathrm{~cm}^{-1}$ at 70 wt. $\%$ [Bmim]Cl. ATR-FTIR spectra demonstrated that the imidazolium cation of $[\mathrm{Bmim}] \mathrm{Cl}$ has interacted with hydroxyl, carbonyl, ether and sulfate groups of the polymer host. Meanwhile, chloride ion was 
preferable to interact with a protonated hydroxyl group, $\mathrm{OH}_{2}^{+}$. The slight decrease of ionic conductivity value at 80 and $100 \mathrm{wt}$. $\%$ of [Bmim] $\mathrm{Cl}$ has shown that the plasticizing effect of $[\mathrm{Bmim}] \mathrm{Cl}$ has softened the polymer backbone thus maintained the magnitude $10^{-3} \mathrm{~S} \mathrm{~cm}^{-1}$ of the conductivity. These results can be attributed with the XRD analysis of the film in which the lowest DC exhibited by iota carrageenan is $14.1 \%$ at $70 \mathrm{wt}$ \% of [ $\mathrm{Bmim}] \mathrm{Cl}$. The morphology result has shown that ionic liquid, [Bmim]Cl is compatible with iota carrageenan and possesses the most homogeneous film at $70 \mathrm{wt}$ \% of [Bmim]Cl. The LSV analysis indicated that the electrochemical stability of iota carrageenan with the addition of ionic liquid was stable up to $3.0 \mathrm{~V}$. The transference number measurement shows that ions are the main contributor for the polymer electrolyte conduction. These results indicated that iota-carrageenan based solid polymer electrolyte with the ionic liquid, [Bmim] $\mathrm{Cl}$ has a potential to be applied for electrochemical device application.

\section{ACKNOWLEDGEMENTS}

The authors would like to thank UKM for the provision of grants 07-01-02-SF1321 and GUP-2017-014.

\section{REFERENCES}

Agrawal, R.C. \& Pandey, G.P. 2008. Solid polymer electrolytes: Materials designing and all-solid-state battery applications: An overview. Journal of Physics D: Applied Physics 41(22): 223001.

Anderson, J.L., Armstrong, D.W. \& Wei, G.T. 2006. Ionic liquids in analytical chemistry. Analytical Chemistry 78(9): 2892-2902.

Armand, M., Endres, F., MacFarlane, D.R., Ohno, H. \& Scrosati, B. 2009. Ionic-liquid materials for the electrochemical challenges of the future. Nature Materials 8(8): 621-629.

Avent, A.G., Chaloner, P.A., Day, M.P., Seddon, K.R. \& Welton, T. 1994. Evidence for hydrogen bonding in solutions of 1-ethyl-3-methylimidazolium halides, and its implications for room-temperature halogenoaluminate (III) ionic liquids. Journal of the Chemical Society, Dalton Transactions 23: 3405-3413.

Arof, A.K., Shuhaimi, N.E.A., Alias, N.A., Kufian, M.Z. \& Majid, S.R. 2010. Application of chitosan/iota-carrageenan polymer electrolytes in electrical double layer capacitor (EDLC). Journal of Solid State Electrochemistry 14(12): 2145-2152.

Borderías, A.J., Sánchez-Alonso, I. \& Pérez-Mateos, M. 2005. New applications of fibres in foods: Addition to fishery products. Trends in Food Science \& Technology 16(10): 458-465.

Bešter-Rogač, M., Stoppa, A., Hunger, J., Hefter, G. \& Buchner, R. 2011. Association of ionic liquids in solution: A combined dielectric and conductivity study of $[\mathrm{bmim}][\mathrm{Cl}]$ in water and in acetonitrile. Physical Chemistry Chemical Physics 13(39): 17588-17598.

Campo, V.L., Kawano, D.F., da Silva Jr., D.B. \& Carvalho, I. 2009. Carrageenans: Biological properties, chemical modifications and structural analysis-A review. Carbohydrate Polymers 77(2): $167-180$.
Cláudio, A.F.M., Swift, L., Hallett, J.P., Welton, T., Coutinho, J.A. \& Freire, M.G. 2014. Extended scale for the hydrogenbond basicity of ionic liquids. Physical Chemistry Chemical Physics 16(14): 6593-6601.

Coggins, C., Blanchard, K., Alvarez, F., Brache, V., Weisberg, E., Kilmarx, P.H., Lacarra, M., Massai, R., Mishell, D., Salvatierra, A. \& Witwatwongwana, P. 2000. Preliminary safety and acceptability of a carrageenan gel for possible use as a vaginal microbicide. Sexually Transmitted Infections 76(6): 480-483.

Ghani, N.A.A., Othaman, R., Ahmad, A., Anuar, F.H. \& Hassan, N.H. 2018. Impact of purification on iota carrageenan as solid polymer electrolyte. Arabian Journal of Chemistry 12(3): 370-376.

Giridhar, P., Venkatesan, K.A., Srinivasan, T.G. \& Rao, P.V. 2007. Electrochemical behavior of uranium (VI) in 1-butyl3-methylimidazolium chloride and thermal characterization of uranium oxide deposit. Electrochimica Acta 52(9): 30063012.

Jumaah, F.N., Mobarak, N.N., Ahmad, A., Ghani, M.A. \& Rahman, M.Y. 2015. Derivative of iota-carrageenan as solid polymer electrolyte. Ionics 21(5): 1311-1320.

Jumaah, F.N., Mobaraka, N.N., Ahmad, A. \& Ramli, N. 2013. Characterization of $\mathrm{r}$-carrageenan and its derivative based green polymer electrolytes. AIP Conference Proceedings 1571(1): 768-774.

Jayakumar, M., Venkatesan, K.A. \& Srinivasan, T.G. 2007. Electrochemical behavior of fission palladium in 1-butyl-3methylimidazolium chloride. Electrochimica Acta 52(24): 7121-7127.

Liu, Z., Wang, H., Li, Z., Lu, X., Zhang, X., Zhang, S. \& Liu Zhou, K. 2011. Characterization of the regenerated cellulose films in ionic liquids and rheological properties of the solutions. Materials Chemistry and Physics 128(1-2): 220-227.

Liew, C.W., Ramesh, S. \& Arof, A.K. 2014. A novel approach on ionic liquid-based poly (vinyl alcohol) proton conductive polymer electrolytes for fuel cell applications. International Journal of Hydrogen Energy 39(6): 2917-2928.

Mobarak, N.N., Jumaah, F.N., Ghani, M.A., Abdullah, M.P. \& Ahmad, A. 2015. Carboxymethyl carrageenan-based biopolymer electrolytes. Electrochimica Acta 175: 224-231.

Mobarak, N.N., Ramli, N., Ahmad, A. \& Rahman, M.Y.A. 2012. Chemical interaction and conductivity of carboxymethyl $\kappa$-carrageenan based green polymer electrolyte. Solid State Ionics 224: 51-57.

Moniha, V., Alagar, M., Selvasekarapandian, S., Sundaresan, B. \& Boopathi, G. 2018. Conductive bio-polymer electrolyte iota-carrageenan with ammonium nitrate for application in electrochemical devices. Journal of Non-Crystalline Solids 481: 424-434.

Ng, L.S. \& Mohamad, A.A. 2006. Protonic battery based on a plasticized chitosan-NH4NO3 solid polymer electrolyte. Journal of Power Sources 163(1): 382-385.

Osman, Z. \& Arof, A.K. 2003. FTIR studies of chitosan acetatebased polymer electrolytes. Electrochimica Acta 48(8): 993-999.

Paula, G.A., Benevides, N.M., Cunha, A.P., de Oliveira, A.V., Pinto, A.M., Morais, J.P.S. \& Azeredo, H.M. 2015. Development and characterization of edible films from mixtures of $\kappa$-carrageenan, 1-carrageenan, and alginate. Food Hydrocolloids 47: 140-145.

Rani, M.S.A., Hassan, N.H., Ahmad, A., Kaddami, H. \& Mohamed, N.S. 2016. Investigation of biosourced 
carboxymethyl cellulose-ionic liquid polymer electrolytes for potential application in electrochemical devices. Ionics 22(10): 1855-1864.

Shamsudin, I.J., Ahmad, A., Hassan, N.H. \& Kaddami, H. 2015a. Biopolymer electrolytes based on carboxymethyl K-carrageenan and imidazolium ionic liquid. Ionics 22(6): 841-851.

Shamsudin, I.J., Ahmad, A., Hassan, N.H. \& Kaddami, H. 2015 b. Bifunctional ionic liquid in conductive biopolymer based on chitosan for electrochemical devices application. Solid State Ionics 278: 11-19.

Shamsudin, I.J., Ahmad, A. \& Hassan, N.H. 2014. Green polymer electrolytes based on chitosan and 1-butyl3-methylimidazolium acetate. AIP Conference Proceedings 1614(1): 393-398.

Sun, P. \& Armstrong, D.W. 2010. Ionic liquids in analytical chemistry. Analytica Chimica Acta 661(1): 1-16.

Tanner, K.E., Draper, P.R., Getz, J.J., Burnett, S.W. \& Youngblood, E. 2002. RP Scherer Technologies Inc. Film forming compositions comprising modified starches and iota-carrageenan and methods for manufacturing soft capsules using same. U.S. Patent.

Vila, J., Varela, L.M. \& Cabeza, O. 2007. Cation and anion sizes influence in the temperature dependence of the electrical conductivity in nine imidazolium based ionic liquids. Electrochimica Acta 52(26): 7413-7417.
Woo, H.J., Majid, S.R. \& Arof, A.K. 2011. Conduction and thermal properties of a proton conducting polymer electrolyte based on poly ( $\varepsilon$-caprolactone). Solid State Ionics 199: 14-20.

Nur Azlina Abdul Ghani, Farah Hannan Anuar, Azizan Ahmad, Nadhratun Naiim Mobarak, Mariah Zuliana Dzulkipli \& Nur Hasyareeda Hassan*

Centre for Advance Material and Renewable Resources

Faculty of Science and Technology

Universiti Kebangsaan Malaysia

43600 UKM Bangi, Selangor Darul Ehsan

Malaysia

Intan Juliana Shamsudin

Chemistry Department

Centre for Defence Foundation Studies

National Defence University of Malaysia

57000 Kuala Lumpur, Federal Territory

Malaysia

*Corresponding author; email: syareeda@ukm.edu.my

Received: 5 December 2018

Accepted: 27 October 2019 
